\begin{tabular}{|c|c|}
\hline Title & Potential role of sensory bias in plumage pattern evolution : termite eating and polka dots in estrildid finches \\
\hline Author(s) & Mizuno, Ayumi; Soma, Masayo \\
\hline Citation & $\begin{array}{l}\text { Ethology, ecology \& evolution, 33(1), 49-61 } \\
\text { https://doi .org/10.1080/03949370.2020.1803414 }\end{array}$ \\
\hline Issue Date & $2021-08-25$ \\
\hline DOC URL & http:/hdl.handle.net/2115/82515 \\
\hline Rights & $\begin{array}{l}\text { This is an A ccepted Manuscript of an article published by Taylor \& Francis in Ethology, ecology \& evolution on } 25 \\
\text { A ug 2020, available online: http://www.tandfonline.com/10.1080/03949370.2020.1803414 }\end{array}$ \\
\hline Type & article (author version) \\
\hline File Information & Ethol. Ecol. Evol.33-1_49-61.pdf \\
\hline
\end{tabular}

Instructions for use 


\title{
Potential role of sensory bias in plumage pattern evolution: termite-eating and polka-dots in estrildid finches
}

\author{
AYUMI MizUnO ${ }^{1}$ and MASAYo SOMA ${ }^{2, *}$
}

${ }^{1}$ Biosystems Science Course, The Graduate School of Life Science, Hokkaido University, Kita 10

Nishi 8, Kita-ku, Sapporo, Hokkaido 060-0810, Japan

${ }^{2}$ Department of Biology, Faculty of Science, Hokkaido University, Kita 10 Nishi 8, Kita-ku,

Sapporo, Hokkaido 060-0810, Japan

*Corresponding author:

Masayo Soma,

Department of Biology, Faculty of Science, Hokkaido University,

Kita 10 Nishi 8, Kita-ku, Sapporo, Hokkaido 060-0810, Japan

(E-mail: masayo.soma@sci.hokudai.ac.jp). 


\begin{abstract}
Conspicuous colour patterns of animals, such as dots or stripes, can function as sexual and/or social signals. Their evolution is often explained by honest indicator mechanisms or the sensory exploitation hypothesis. In birds, however, the latter scenario has been scarcely tested. According to the sensory exploitation hypothesis, prey-like colour patterns can evolve when they contribute to attracting opposite-sex conspecifics by hitchhiking pre-existing sensory systems (sensory bias) that help foraging. Even without cheating scenarios, visual systems can serve as an underlying factor that facilitates the evolution of both foraging behaviours and colour patterns on the body. To test this idea, we examined the relationship between bird plumage patterns and diet using phylogenetic comparative approaches. Specifically, we focused on white polka-dot plumage patterns in estrildid finches and tested whether such patterns evolved for visual sensory systems that help foraging termites and other gregarious whitish small round prey items. Although we predicted that white polka-dots exist in termite-eater species, and that termite-eating evolved before the white polka-dot pattern, ancestral reconstruction did not reveal clear ancestral states for termite-eating. However, the phylogenetic regression model showed that species with conspicuous white polka-dots tended to be termite-eaters. We also found that estrildids with white polka-dots were likely to become termite-eaters, while those without white polka-dots were likely to become non-termite eaters, according to evolutionary transition analysis. These results are in contrast to the prediction of sensory exploitation hypothesis, wherein diet is believed to trigger the evolution of plumage patterns. However, the results presented here suggest that pre-existing sensory bias for white dots may have promoted the evolution of both termite-eating and white polka-dot plumage patterns in estrildids.
\end{abstract}

\title{
KEY WORDS:
}

estrildid finch, phylogenetic comparison, plumage colour pattern, sensory bias, sensory exploitation, signal, termite. 


\section{INTRODUCTION}

The sensory exploitation hypothesis posits that signallers derive reproductive benefits from exploiting the pre-existing sensory bias of receivers, originally shaped for foraging or predator avoidance (Ryan 1990, 1998; Ryan \& Keddy-Hector 1992; Endler \& Basolo 1998; Rodríguez \& Snedden 2004). Typically, if males have ornamentation that mimics food, they become successful in mating by attracting females that have a sensory bias for the food that is being mimicked. In this way, males may have evolved sexual traits that attract the attention of females by hitchhiking pre-existing sensory systems of females (Ryan 1990, 1998; Endler \& Basolo 1998).

Several studies support the sensory exploitation hypothesis of sexual signals. For example, male guppies (Poecilia reticulata) exploit female visual sensory bias for food (Rodd et al. 2002). They display orange spots on the body, which resemble fruits that are hard to find but preferred by guppies, and stimulate females seeking valuable fruits (Rodd et al. 2002). Male water mites (Neumania papillator) use a vibration signal that mimics their prey by trembling their legs, attracting females by exploiting their prey-detection mechanisms (Proctor 1991, 1992). Despite numerous previous empirical studies on a range of species, the hypothesis has not been well examined for the evolution of visual traits in birds (Ryan 1998; Rodríguez \& Snedden 2004). Exceptionally in bowerbirds (Ptilonorhynchidae), the colour of the decorations of these birds used for male courtship was claimed to match with female colour preference when foraging (Madden \& Tanner 2003; but see also Borgia \& Keagy 2006). In addition, in male jungle fowls (Gallus gallus), their wattle ornamentations function for enhancing food-related visual displays (Schenkel 1956; Stokes \& Williams 1971; Smith et al. 2009). Several other avian studies in line with the sensory exploitation hypothesis focused on the presence of sensory bias, but did not investigate whether males actually deceive females (e.g. Burley \& Symanski 1998; Collins 1999; Jones \& Hunter 1999). 
Birds are characterized by conspicuous or cryptic plumage patterns, which are likely to have evolved for intraspecific communications or as a result of predator-prey interactions, respectively (Roulin 1999b; Bortolotti et al. 2006; Gluckman 2014; Marshall \& Gluckman 2015; Soma \& Garamszegi 2018). The signalling function of patterns is often explained in light of honest indicator mechanisms, which propose that vivid colours or distinct patterns are possessed by individuals with better conditions as honest signals of an individual's quality (Zahavi 1975, 1977; Hamilton \& Zuk 1982; Andersson 1986). Supporting this view, in zebra finches (Taeniopygia guttata), black and white stripes on the chest of the males represent early nestling diets (Birkhead et al. 1999), and females prefer males with symmetric chest stripes (Swaddle \& Cuthill 1994). Similarly, in common waxbills (Estrilda astrild), the regularity of barred plumage reflects body condition, especially in adult males (Marques et al. 2016). While these studies focus on male phenotypic variations and the female preferences, in barn owls (Tyto alba), males are known to assess female quality according to the spottiness of the plumage of the females (Roulin 1999b). Female barn owls have more spots than males (Roulin 1999a), where the spots are representative of parasite resistance (Roulin et al. 2001).

What has remained a mystery until now is why a particular type of plumage patterns (e.g. colour combinations or shape of the pattern motif) evolved in each species. In order to gain an evolutionary understanding of the plumage colour patterns of different birds, it would be of help to investigate the role of foraging-related sensory bias. Prey-like colour patterns are known to have evolved in fish (Rodd et al. 2002; Garcia \& Ramirez 2005), which could be explained by deception mechanisms as predicted by the sensory exploitation hypothesis, and can also solely be attributed to shared visual mechanisms beneficial for the detection of foods and the identification of conspecifics (sensory bias). In other words, having sensitivity for a particular colour may contribute to the successful foraging of food and the identification of conspecifics in the same colour. For a similar reason, being able to see or pay attention to small dots or stripes (higher visual acuity) can help in both the visual detection of small/thin prey items and the identification 
of finely patterned conspecific individuals. This is why, here, we predict that a sensory bias for termite-eating may have caused the evolution of white polka-dot patterns in birds.

Estrildid finches (family Estrildidae) are good subjects to test the idea that diet-driven sensory bias contributed to the evolution of plumage colour patterns. Estrildid finches are gregarious socially monogamous songbirds with varying degrees of coloniality and plumage dichromatism (Goodwin 1982). In over $25 \%$ of estrildid species, both males and females have white polka-dot plumages, which have been suggested to have serve a signalling function (Soma \& Garamszegi 2018) (see examples in Fig. 1a-d). Specifically, they show social and sexual displays in a close distance often on the same perch (Goodwin 1982; Soma \& Garamszegi 2015), where dots on the flank (Fig. 1) could serve as a clue for individual identification or social/sexual signals. Supporting this idea, a species of estrildid finch, diamond firetails (Stagonopleura guttata, Fig. 1a), have white polka-dot patterns on its flank, and the number of dots is associated with its physical condition (Zanollo et al. 2012) and social dominance in females (Crowhurst et al. 2012). We hypothesized that these white polka-dot patterns evolved due to a sensory bias that facilitates foraging behaviour for whitish small round prey often found in swarms, such as termites and ant larvae or eggs. Actually, red-headed finches (Amadina erythrocephala) are known to take harvester termites (Hodotermes mossambicus), and star finches (Neochmia ruficauda) eat giant northern termites (Mastotermes darwiniensis) (Goodwin 1982). Uraeginthus spp. also eat Odontotermes (Hamed \& Evans 1984) or Macrotermes (Yamashina 2014). In captivity, western bluebills (Spermophaga haematina) eat house fly maggots (Musca domestica) (Goodwin 1982). These prey are regularly consumed in some estrildid species, as they ensure the protein intake needed for the breeding season is met. However, estrildid finches are generally grain-eaters.

In this study, we tested our hypothesis that white polka-dot patterns in estrildid finches evolved in species foraging small, round, white gregarious insects by using phylogenetic comparative approaches. First, we performed ancestral state reconstruction on white polka-dot 
patterns and eating termites (including other gregarious round invertebrates) to determine whether foraging preceded the evolution of sexual characteristics, as is often depicted in notable examples of sensory exploitation (Ryan 1998). Second, we examined the correlation between the evolution of white polka-dot patterns and termite-eating using phylogenetic regression models. Finally, we tested the evolutionary transition between the two traits (i.e. termite-eating and polka-dots).

\section{MATERIAL AND METHODS}

\section{Data collection}

We collected data on the diets of 134 estrildid species based on the literature: "Estrildid finches of the world" (Goodwin 1982) and "Handbook of the birds of the world. Vol. 15" (Payne 2010). We verified whether each species feeds on whitish round gregarious forms of invertebrates, which included termites, and the eggs, larvae, and pupae of ants, but did not include winged-termites because of their colour, shape, and mobility. For convenience, those species that were found to feed on round invertebrates will be denoted as termite-eaters hereafter. Furthermore, in order to consider the alternative possibility, that the invertebrate protein diet influences the plumage patterns regardless of the colour and shape of the prey, we checked whether each species feeds on any invertebrates, which included ants, spiders, caterpillars, and worms (referred to as invertebrate-eaters, hereafter). In this way, each estrildid species was categorized as termite- or non-termite eater, and invertebrate- or non-invertebrate eater, wherein invertebrate-eating species encompassed all termite-eating species. Due to the limited information available in the literature, we were not able to identify the prey species. It should be also noted that the above categorizations (i.e. termite-eater and invertebrate-eater) included only those species regularly consuming each diet.

We collected data on the presence/absence of white polka-dot patterns in 134 species of estrildid finches based on the descriptions of the above two books (Goodwin 1982; Payne 2010). 
Polka-dot patterns were defined as white dots appearing regularly and repeatedly on plumage, as the members of this family of birds do not ever have black or red dots. We scored the presence and absence of these dot patterns as 1 and 0, respectively. The plumage of males and females within a species was checked separately since some species have plumage dichromatism. Additionally, we scored the conspicuousness of dots by taking the diameter of the dots (in $\mathrm{cm}$ ) in both males and females based on the data obtained from Soma and Garamszegi (2018), in which diameter was scored as 0 for species without dots. Although some estrildids have UV vision (Ödeen \& Håstad 2003), there was no pattern in the nonvisible part of the spectrum that was apparent only under UV light (Soma \& Garamszegi 2018). As males and females can differ with respect to the presence of white polka-dot patterns, we repeated the analyses for male and female datasets, which scored the presence of dots in males or females of each species respectively. The same analyses were also carried out for the species dataset used to score for the presence of dots on either or both sexes.

\section{Phylogeny}

For the phylogenetic comparative analyses, we were unable to obtain a compelling consensus phylogenetic tree with branch lengths of estrildid finches, but we were able to derive multiple alternative trees from https://birdtree.org (Jetz et al. 2012), which was sufficient to control for the phylogenetic uncertainty for our analyses. We used 1000 trees from the dataset for the analyses described in the following section.

\section{Phylogenetic comparative analyses}

Ancestral state reconstruction. To determine the evolutionary history of diet (termite-eating and invertebrate-eating) and white polka-dots in male and female estrildid finches, we performed ancestral state reconstructions. We used the maximum-likelihood method using the R package "phytools" (Revell 2012), wherein 1000 phylogenetic trees were used repeatedly for the ancestral 
state reconstructions. The outcomes were averaged to calculate the likelihood of common ancestral states. When averaging each likelihood, we weighted the parameter estimates based on the AIC of the respective model corresponding to an individual tree (Garamszegi \& Mundry 2014).

Regression models. To elucidate the phylogenetic relationship between white polka-dots and termite-eating, we built regression models in two ways. First, to test whether termite-eating affects polka-dots, we conducted phylogenetic logistic regression analysis using the function phyloglm in the R package "phylolm" (Ho et al. 2018). In the phylogenetic logistic regression models, termite-eating or invertebrate-eating were used as explanatory variables, while the presence/absence of white polka-dots in each sex was used as a response variable, using the male and female datasets. We used the same set of 1000 phylogenetic trees as those used for the ancestral reconstructions, from which we obtained the model-averaged mean coefficients, standard errors (SEs), and 95\% confidence intervals (CIs). When averaging the models, we weighted the parameter estimates based on the AIC of the respective model corresponding to an individual tree (Garamszegi \& Mundry 2014). Second, we tested whether polka-dot conspicuousness affects termite-eating using the male and female datasets. We fitted Phylogenetic Generalized Least Squares (PGLS) regressions, in which white polka-dots size was used as an explanatory variable and the termite-eating/invertebrate-eating was used as a response variable using the R packages "ape” (Paradis \& Schliep 2018) and “caper” (Orme et al. 2018). We repeatedly fitted the same model using each of the 1000 phylogenetic trees and obtained the mean and CI for the estimated parameters by model averaging the 1000 outcomes. To average 1000 outcomes, we used the parameters weighted by AIC for each model corresponding to an individual tree (Garamszegi \& Mundry 2014). All analyses were carried out in R 3.5 .1 (R Development Core Team 2018). 
Evolutionary transition analyses. To estimate the evolutionary transitions between the presence/absence of white polka-dots in association with the presence/absence of termite-eating, we used discrete modules of the maximum likelihood function of BayesTraits V 3.0.1 (Meade \& Pagel 2017). Firstly, we compared a dependent model, wherein white polka-dots and termite-eating evolved dependently, with an independent model, wherein these traits evolved independently. Secondly, we investigated the direction of the significant evolutionary transition by sequentially restricting all eight possible changes in the character state of the dependent model to zero and comparing these to the original model. The significance of the model comparisons was determined using likelihood rate tests (LR tests), with $\alpha$ set at $0.05(P<0.05)$. Likelihoods were estimated using 1000 optimization attempts per run. We reported the model-averaged estimates from 1000 alternative trees based on the log-likelihood of the model. In addition, in order to investigate whether eating invertebrates affects the presence of white polka-dots regardless of their shape or colour, we also ran the same analyses for the transitions between invertebrate-eating and white polka-dots. These analyses were repeatedly performed using species or male/female datasets for dots.

\section{RESULTS}

Among the 134 estrildid finches, 30 species had white polka-dots in both sexes, while a few species show male-biased or female-biased sexual dichromatism in the presence of polka-dots. Specifically, the females of 34 species and the males of 31 species in total had white polka-dots. 61 species of estrildids ( $46 \%$ ) are termite-eaters. More than $65 \%$ of the termite-eaters had white polka-dot patterns on their plumages (females: 23 out of 34 species, males: 21 out of 31 species), whereas less than $40 \%$ of the non-termite eating species had white polka-dots (females: 38 out of 98 species, males: 40 out of 101 species).

Ancestral state reconstruction 
The ancestral states for termite-eating were unclear, since the reconstruction showed that the likelihood of having each trait was almost equal to that of lacking it (proportional likelihood of termite-eating $=0.517)$. On the other hand, common ancestors were found to have a high likelihood of invertebrate-eating (proportional likelihood of invertebrate-eater $=0.989$ ). The estimated ancestral state for white polka-dots revealed that common ancestors did not have white polka-dot plumage patterns (proportional likelihood of white polka-dots on males $=0.039$, proportional likelihood of white polka-dots on females $=0.042$ ).

\section{Correlations between white polka-dots and diets}

Using the male and female datasets, we performed two sets of regression models, testing the effects of diet on the presence of white dots, and the effects of dot size on diet. We did not find a significant effect of termite-eating on the presence of white polka-dot patterns on their plumages (Table 1). Likewise, we did not find a significant effect of invertebrate-eating on the presence of white polka-dots (Table 1). Conversely, we found that the diameter of white polka-dot had a significant positive effect on the presence of termite-eating in estrildids (Table 2a, Fig. 2), while invertebrate-eating was not affected by the diameter of white polka-dot (Table $2 b$, Fig. 2).

\section{Evolutionary transitions}

The evolutionary transition analyses supported the idea that white polka-dots and termite-eating evolved significantly dependently at the species level (species datasets: average $\mathrm{LR}=11.176, \mathrm{df}=4, P=0.025$; Fig. 3 ). When we conducted the same analyses in males and females separately, we found that these two traits evolved dependently in the female dataset, but not in the male dataset (female dataset: average $\mathrm{LR}=10.265$, $\mathrm{df}=4, P=0.036$, male dataset: average $\mathrm{LR}=8.769, \mathrm{df}=4, P=0.067)$. There was no statistically significant difference between 
the evolutionary models that white polka-dots and invertebrate-eating evolved independently, and those models that evolved dependently (species datasets: average $\mathrm{LR}=6.766$, $\mathrm{df}=4, P=0.149$ ).

Further evolutionary transition analyses on the species dataset revealed that white polka-dot patterns caused the evolution of termite-eating, but not vice versa (Fig. 3). When estrildids were termite-eaters, the evolutionary transitions between the presence and absence of white polka-dots were not statistically significant (gaining white polka-dots: average LR $=0.176$, df $=1, P=0.675$, losing white polka-dots: average $\mathrm{LR}=1.294$, $\mathrm{df}=1, P=0.740$; Fig. 3). Similarly, when estrildids were non-termite eaters, the evolutionary transitions between the presence and absence of white polka-dots were not statistically significant (gaining white polka-dots: average $\mathrm{LR}=1.252 \mathrm{df}=1, P=0.263$, losing white polka-dots: average $\mathrm{LR}=1.294$, $\mathrm{df}=1, P=0.255$; Fig. 3 ). However, estrildids with white polka-dot plumages were more likely to become termite-eaters than non-termite eaters (Fig. 3). Estrildids without white polka-dot patterns were more likely to become non-termite eaters than termite-eaters (Fig. 3).

\section{DISCUSSION}

The results obtained from this phylogenetic comparative study partially support the idea that white polka-dot patterns in estrildids have evolved due to the sensory bias that facilitates termite-eating. Estrildid finches with conspicuous polka-dots (i.e. larger dots) were found to tend to be termite-eaters (Table 2). Moreover, the evolutionary transition analyses revealed that species with polka-dot patterns were likely to become termite-eaters, while those without dots were likely to lose the behaviour of termite-eating (Fig. 3). The evolutionary process revealed from the present study is in contrast with the prediction made using the sensory exploitation hypothesis that diet promotes the evolution of visual signals. These results are rather unexpected, but do not deny the possible role of sensory bias on diet and plumage patterns. Sensory systems that help visual detection or individual identification of conspecifics with dot patterns are likely to be useful for foraging on small gregarious invertebrates appearing as repeated dots, and 
beneficial for protein-rich nutrients (Goodwin 1982; Payne 2010). In addition, we cannot deny the possibility that detected evolutionary transitions might be affected by the limit of information regarding termite-eating.

Although we found a relationship between white dots and termite-eating, it is not probable that white dots directly reflect the dietary nutrition obtained from termites or other invertebrates. White feathers are structurally colourless and made of unpigmented feather keratins, and are therefore assumed to require fewer resources for their production, compared to the feathers of carotenoid- or melanin-based plumages (Jawor \& Breitwisch 2003; Prum 2006). However, it is also unlikely that white plumage ornamentations do not require any maintenance. White feathers are known to be more susceptible to parasites and abrasion than feathers with melanin (Swaddle \& Witter 1995; Kose \& Møller 1999; Griggio et al. 2011), which is the reason why white plumage serves as an ornamentation that is a good indicator of the individual's condition. For example, the whiteness of the tail patches in male dark-eyed juncos (Junco hyemalis) are affected by the quality of their diet (McGlothlin et al. 2007), with whiter males also having larger body sizes and have greater mating success (McGlothlin et al. 2005). In estrildid finches, Diamond firetail (Stagonopleura guttata) females have more white dots along their flanks than males on average (Zanollo et al. 2014, Fig. 1a). The number of dots is representative of the physical condition (Zanollo et al. 2012) and predicts feeding dominance in females (Crowhurst et al. 2012). Although the expression of white dots is likely to be low cost, it may incur a maintenance cost, such that white polka-dots can be considered as a good indicator, as reported in diamond firetails (Crowhurst et al. 2012; Zanollo et al. 2012, 2014). We also assume that it is unlikely that the white polka-dots of estrildids evolved for the purpose of camouflage. In estrildids, dots appear mainly on the ventral side, and in some species dots are tiny and small in number (Fig. 1b and 1d), which would be ineffective for camouflage.

Within the literature on the sensory exploitation hypothesis (Ryan 1990, 1998; Endler \& Basolo 1998), few studies have investigated the possibility of female traits evolving in parallel 
with male traits (e.g. Funk \& Tallamy 2000). It is often the case that females are seen as victims of male deception. However, considering that males and females are likely to share the same sensory systems for foraging and surviving, both sexes may be attracted by similar stimuli. For example, in some Goodeinae species, in which males have terminal yellow bands (TYB) on their tails, used to attract the females by exploiting their prey-detection system (Garcia \& Ramirez 2005), both males and females have been found to bite tails with conspicuous TYB (Garcia \& Ramirez 2005). This indicates that mutual deception may lead to the evolution of prey-like patterns in both sexes. Otherwise, sensory systems shared between sexes also explain mutual ornamentations that do not involve any deception scenario, especially when such ornamentations are used for individual recognition and social signalling. This idea is supported by the fact that white dotted patterns are found in both sexes in many estrildid species, where only a few species have sexually-biased white dots (i.e. where only the males or females have white polka-dots). Furthermore, females often have more dots than males in an estrildid species (Zanollo et al. 2012, Fig. 1a). As such, the white dot ornamentations found on the plumage of estrildids may play an important role in recognizing conspecifics in addition to their function as sexual signals.

Lastly, we would like to stress that this is the first interspecific comparative study that shed light on the possible relationship between visual system and avian plumage evolution, and that there should be more scrutiny. Even for estrildid plumage ornamentation, we can think of other scenarios than what we proposed in the present study. Considering that all estrildids eat small grass seeds that are often round and pale, we suspect that there might be a relationship between seed size/shape and plumage pattern, which should be examined in the future.

\section{ACKNOWLEDGEMENT}

This study was supported by the JSPS Grant-in-Aid for Young Scientists (23680027 and 16H06177) to Masayo Soma. 


\section{REFERENCES}

Andersson M. 1986. Evolution of condition-dependent sex ornaments and mating preferences: sexual selection based on viability differences. Evolution. 40:804-816. doi:10.1111/j.1558-5646.1986.tb00540.x

Birkhead TR, Fletcher F, Pellatt EJ. 1999. Nestling diet, secondary sexual traits and fitness in the zebra finch. Proc R Soc Lond B. 266:385-390. doi:10.1098/rspb.1999.0649

Borgia G, Keagy J. 2006. An inverse relationship between decoration and food colour preferences in satin bowerbirds does not support the sensory drive hypothesis. Anim Behav. 72:1125-1133. doi:10.1016/j.anbehav.2006.03.015

Bortolotti GR, Blas J, Negro JJ, Tella JL. 2006. A complex plumage pattern as an honest social signal. Anim Behav. 72:423-430. doi:10.1016/j.anbehav.2006.01.016

Burley NT, Symanski R. 1998. "A taste for the beautiful": Latent aesthetic mate preferences for white crests in two species of Australian grassfinches. Am Nat. 152:792-802. doi:10.1086/286209

Collins SA. 1999. Is female preference for male repertoires due to sensory bias? Proc R Soc Lond B. 266:2309-2314. doi:10.1098/rspb.1999.0924

Crowhurst CJ, Zanollo V, Griggio M, Robertson J, Kleindorfer S. 2012. White flank spots signal feeding dominance in female diamond firetails, Stagonopleura guttata. Ethology. 118:63-75. doi:10.1111/j.1439-0310.2011.01986.x

Endler JA, Basolo AL. 1998. Sensory ecology, receiver biases and sexual selection. Trends Ecol Evol. 13:415-420. doi:10.1016/S0169-5347(98)01471-2

Funk DH, Tallamy DW. 2000. Courtship role reversal and deceptive signals in the long-tailed dance fly, Rhamphomyia longicauda. Anim Behav. 59:411-421. doi:10.1006/anbe. 1999.1310 
Garamszegi LZ, Mundry R. 2014. Modern phylogenetic comparative methods and their application in evolutionary biology: Multimodel-inference in comparative analyses. Berlin: Springer-Verlag. doi:10.1007/978-3-662-43550-2_12

Garcia CM, Ramirez E. 2005. Evidence that sensory traps can evolve into honest signals. Nature. 434:501-505. doi:10.1038/nature03363

Gluckman TL. 2014. Pathways to elaboration of sexual dimorphism in bird plumage patterns. Biol J Linn Soc Lond. 111:262-273. doi:10.1111/bij.12211

Goodwin D. 1982. Estrildid finches of the world. New York: Cornell University Press.

Griggio M, Valera F, Casas-Crivillé A, Hoi H, Barbosa A. 2011. White tail markings are an indicator of quality and affect mate preference in rock sparrows. Behav Ecol Sociobiol. 65:655-664. doi:10.1007/s00265-010-1067-0

Hamed DM, Evans SM. 1984. Social influences on foraging behaviour of the Red cheeked Cordon Bleu Uraeginthus bengalus Estrildidae. Ibis. 126:156-167. doi:10.1111/j.1474-919X.1984.tb07995.x

Hamilton WD, Zuk M. 1982. Heritable true fitness and bright birds: a role for parasites? Science. 218:384-387. doi:10.1126/science.7123238

Ho LST, Ane C, Lachlan R, Tarpinian K, Feldman R, Yu Q, Biji WVD. 2018. Package "phylolm": Phylogenetic Linear Regression. Available from: https://CRAN.R-project.org/package=phylolm [Accessed 1 Oct 2018]

Jawor JM, Breitwisch R. 2003. Melanin ornaments, honesty, and sexual selection. Auk. 120:249_ 265, doi:10.1093/auk/120.2.249

Jetz W, Thomas GH, Joy JB, Hartmann K, Mooers AO. 2012. The global diversity of birds in space and time. Nature. 491:444-448. doi:10.1038/nature11631

Jones IL, Hunter FM. 1999. Experimental evidence for mutual inter- and intrasexual selection favouring a crested auklet ornament. Anim Behav. 57:521-528. doi:10.1006/ANBE.1998.1012 
Kose M, Møller AP. 1999. Sexual selection, feather breakage and parasites: the importance of white spots in the tail of the barn swallow (Hirundo rustica). Behav Ecol Sociobiol. 45:430436. doi:10.1007/s002650050581

Madden JR, Tanner K. 2003. Preferences for coloured bower decorations can be explained in a nonsexual context. Anim Behav. 65:1077-1083. doi:10.1006/anbe.2003.2126

Marques CIJ, Batalha HR, Cardoso GC. 2016. Signalling with a cryptic trait: The regularity of barred plumage in common waxbills. R Soc Open Sci. 3:160195. doi:10.1098/rsos.160195

Marshall KL, Gluckman TL. 2015. The evolution of pattern camouflage strategies in waterfowl and game birds. Ecol Evol. 5:1981-1991. doi:10.1002/ece3.1482

McGlothlin JW, Duffy DL, Henry-Freeman JL, Ketterson ED. 2007. Diet quality affects an attractive white plumage pattern in dark-eyed juncos (Junco hyemalis). Behav Ecol Sociobiol. 61:1391-1399. doi:10.1007/s00265-007-0370-x

McGlothlin JW, Parker PG, Nolan V, Ketterson ED. 2005. Correlational selection leads to genetic integration of body size and an attractive plumage trait in dark-eyed juncos. Evolution. 59:658-671. doi:10.1111/j.0014-3820.2005.tb01024.x

Meade A, Pagel M. 2017. BayesTraits V3. 0. 1. Available from: http://www.evolution.rdg.ac.uk/BayesTraitsV3.0.1/BayesTraitsV3.0.1.html/ [Accessed 1 Oct 2018].

Ödeen A, Håstad O. 2003. Complex distribution of avian color vision systems revealed by sequencing the SWS1 opsin from total DNA. Mol Biol Evol. 20:855-861. doi:10.1093/molbev/msg108

Orme D, Freckleton R, Thomas G, Petzoldt T, Susanne F, Nick I, Pearse W. 2018. Package "caper": Comparative analyses of phylogenetics and evolution in R. Available from: https://CRAN.R-project.org/package=caper/ [Accessed 1 Oct 2018].

Paradis E, Schliep K. 2018. Package "ape": an environment for modern phylogenetics and evolutionary analyses in R. Bioinformatics. 35:526-528. doi:10.1093/bioinformatics/bty633 
Payne RB. 2010. Family Estrildidae (waxbills). In: del Hoyo J et al., editors. Handbook of the birds of the world. Vol. 15. Barcelona: Lynx Edicions; p. 234-377.

Proctor HC. 1991. Courtship in the water mite Neumania papillator: males capitalize on female adaptations for predation. Anim Behav. 42:589-598. doi:10.1016/S0003-3472(05)80242-8

Proctor HC. 1992. Sensory exploitation and the evolution of male mating behaviour: a cladistic test using water mites (Acari: Parasitengona). Anim Behav. 44:745-752. doi:10.1016/S0003-3472(05)80300-8

Prum RO. 2006. Anatomy, physics, and evolution of structural colours, In: Hill GE, McGraw KJ, editors. Bird coloration. Vol. 1. Mechanisms and measurements. Cambridge: Harvard University Press; p. 295-353.

R Development Core Team. 2018. R: A language and environment for statistical computing. Vienna: R Foundation for Statistical Computing. Available from: http://www.R-project.org/ [Accessed 1 Apr 2018].

Revell LJ. 2012. phytools: an R package for phylogenetic comparative biology (and other things). Methods Ecol Evol. 3:217-223. doi:10.1111/j.2041-210X.2011.00169.x

Rodd FH, Hughes KA, Grether GF, Baril CT. 2002. A possible non-sexual origin of mate preference: are male guppies mimicking fruit? Proc R Soc Lond B. 269:475-481. doi:10.1098/rspb.2001.1891

Rodríguez RL, Snedden WA. 2004. On the functional design of mate preferences and receiver biases. Anim Behav. 68:427-432. doi:10.1016/j.anbehav.2003.08.031

Roulin A. 1999a. Delayed maturation of plumage coloration and plumage spottedness in the barn owl (Tyto alba). J Ornithol. 140:193-197. German. doi:10.1007/BF01653598

Roulin A. 1999b. Nonrandom pairing by male barn owls (Tyto alba) with respect to a female plumage trait. Behav Ecol. 10:688-695. doi:10.1093/beheco/10.6.688 
Roulin A, Riols C, Dijkstra C, Ducrest AL. 2001. Female plumage spottiness signals parasite resistance in the barn owl (Tyto alba). Behav Ecol. 12:103-110. doi:10.1093/oxfordjournals.beheco.a000371

Ryan MJ. 1990. Sexual selection, sensory systems and sensory exploitation. In: Futuyma D, Antonovics J, editors. Oxford surveys in evolutionary biology 7. Oxford: Oxford University Press; p. 157-195.

Ryan MJ. 1998. Sexual selection, receiver biases, and the evolution of sex differences. Science. 281:1999-2003. doi:10.1126/science.281.5385.1999

Ryan MJ, Keddy-Hector A. 1992. Directional patterns of female mate choice and the role of sensory biases. Am Nat. 139:S4-S35. doi:10.1086/285303

Schenkel R. 1956. Zur Deutung der Balzleistungen einiger Phasianiden und Tetraoniden [Interpretation of the courtship performance of some Phasianidae and Tetraonidae]. Ornithol Beobachter. 53:182-201. German.

Smith CL, Van Dyk DA, Taylor PW, Evans CS. 2009. On the function of an enigmatic ornament: wattles increase the conspicuousness of visual displays in male fowl. Anim Behav. 78:14331440. doi:10.1016/j.anbehav.2009.07.034

Soma M, Garamszegi LZ. 2015. Evolution of courtship display in Estrildid finches: dance in relation to female song and plumage ornamentation. Front Ecol Evol. 3:4. doi:10.3389/fevo.2015.00004

Soma M, Garamszegi LZ. 2018. Evolution of patterned plumage as a sexual signal in estrildid finches. Behav Ecol. 29:676-685. doi:10.1093/beheco/ary021

Stokes AW, Williams HW. 1971. Courtship feeding in gallinaceous birds. The Auk. 88:543-559. Available from: www.jstor.org/stable/4083749 [Accessed 15 Mar 2020].

Swaddle JP, Cuthill IC. 1994. Female zebra finches prefer males with symmetric chest plumage. Proc R Soc Lond B. 258:267-271. doi:10.1098/rspb.1994.0172 
Swaddle JP, Witter MS. 1995. Chest plumage, dominance and fluctuating asymmetry in female starlings. Proc R Soc Lond B. 260:219-223. doi:10.1098/rspb.1995.0083

Yamashina C. 2014. Importance of bird seed dispersal in the development of characteristic vegetation on termite mounds in north-eastern Namibia. Tropics. 23:33-44. doi:10.3759/tropics.23.33

Zahavi A. 1975. Mate selection - a selection for a handicap. J Theor Biol. 53:205-214. doi:10.1016/0022-5193(75)90111-3

Zahavi A. 1977. The cost of honesty (further remarks on the handicap principle). J Theor Biol. 67:603-605. doi:10.1016/0022-5193(77)90061-3

Zanollo V, Griggio M, Robertson J, Kleindorfer S. 2012. The number and coloration of white flank spots predict the strength of a cutaneous immune response in female Diamond Firetails, Stagonopleura guttata. J Ornithol. 153:1233-1244. doi:10.1007/s10336-012-0855-x

Zanollo V, Griggio M, Robertson J, Kleindorfer S. 2014. Assortative pairings in Diamond Firetails (Stagonopleura guttata) are not the result of mutual mate choice for an ornament. Ethology. 120:951-964. doi:10.1111/eth.12268 

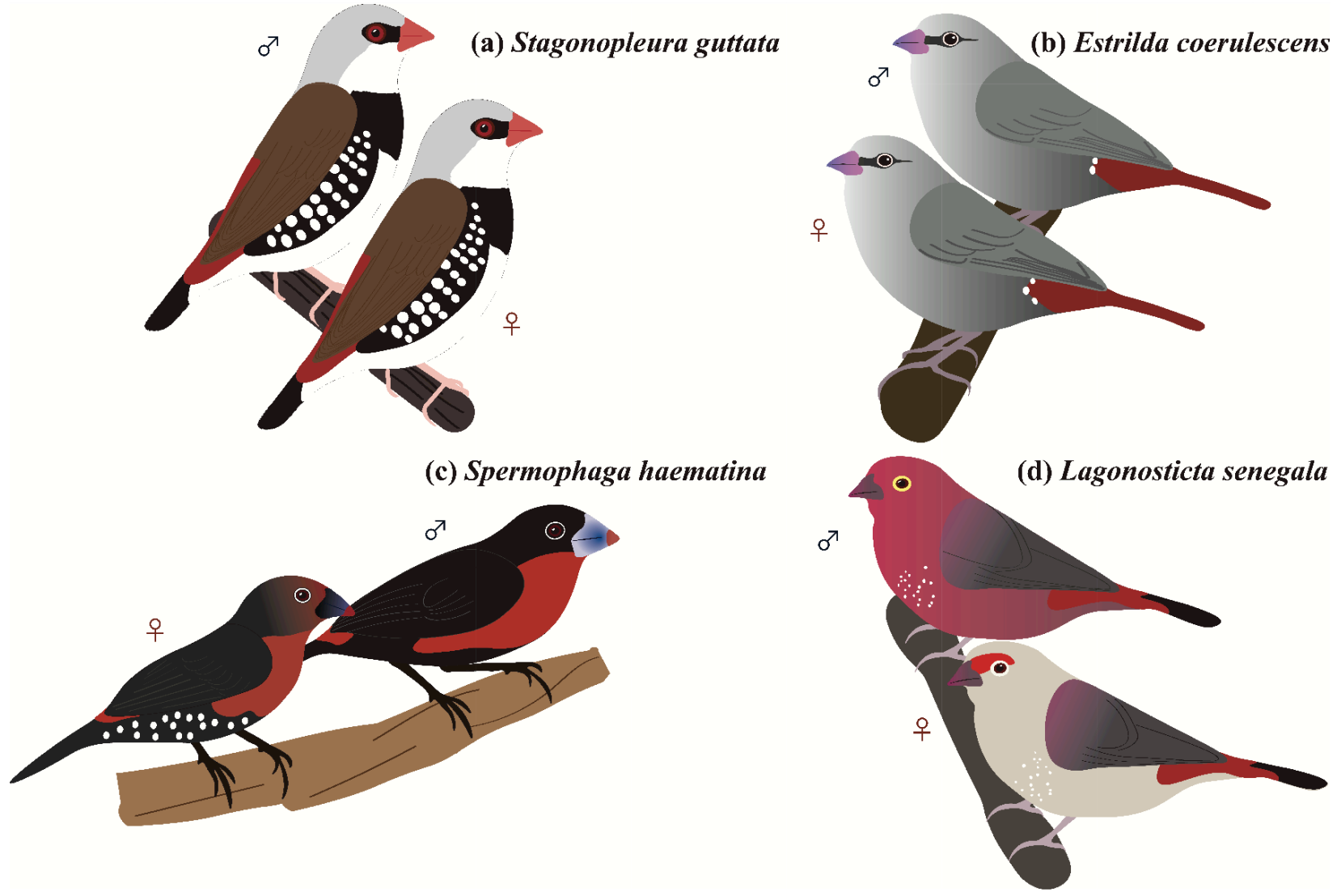

Fig. 1. Examples of interspecific variations and sexual differences in plumage patterns of estrildids (a-d). (a) In diamond firetails (Stagonopleura guttata), females have more polka-dots than males (Crowhurst et al. 2012), where the number of dots reflects the physical condition (Zanollo et al. 2012) and social dominance of females (Crowhurst et al. 2012). (b) In lavender waxbills (Estrilda coerulescens), both males and females have only a few white spots on their under tail-coverts. (c) In western bluebills (Spermophaga haematina), females have white polka-dot patterns. (d) In red-billed firefinches (Lagonosticta senegala), although the body colour is greatly different between males and females, both sexes have almost invisible white dots along their flank and chest. 


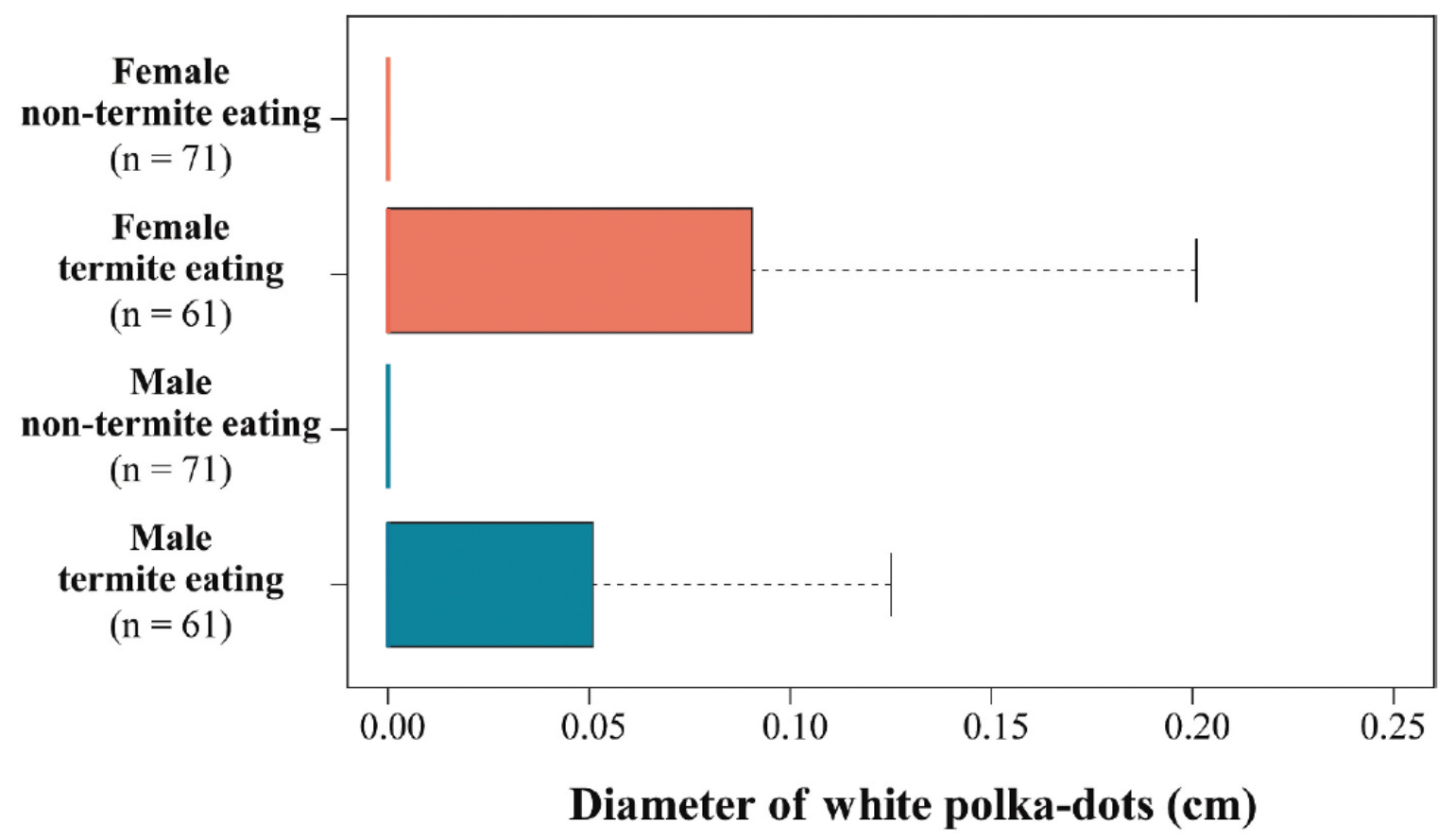

Fig. 2. Comparison of male and female white polka-dots sizes between termite-eater and non-termite eater species. Although termite-eating (vertical axis) is included, the diameter of the white dots in 11 species of females is unknown due to a lack of measurable specimens. The same is true for 10 species of males. Species without dots are shown the graph as " $0.00 \mathrm{~cm}$ ". All box plots denote quartiles. 


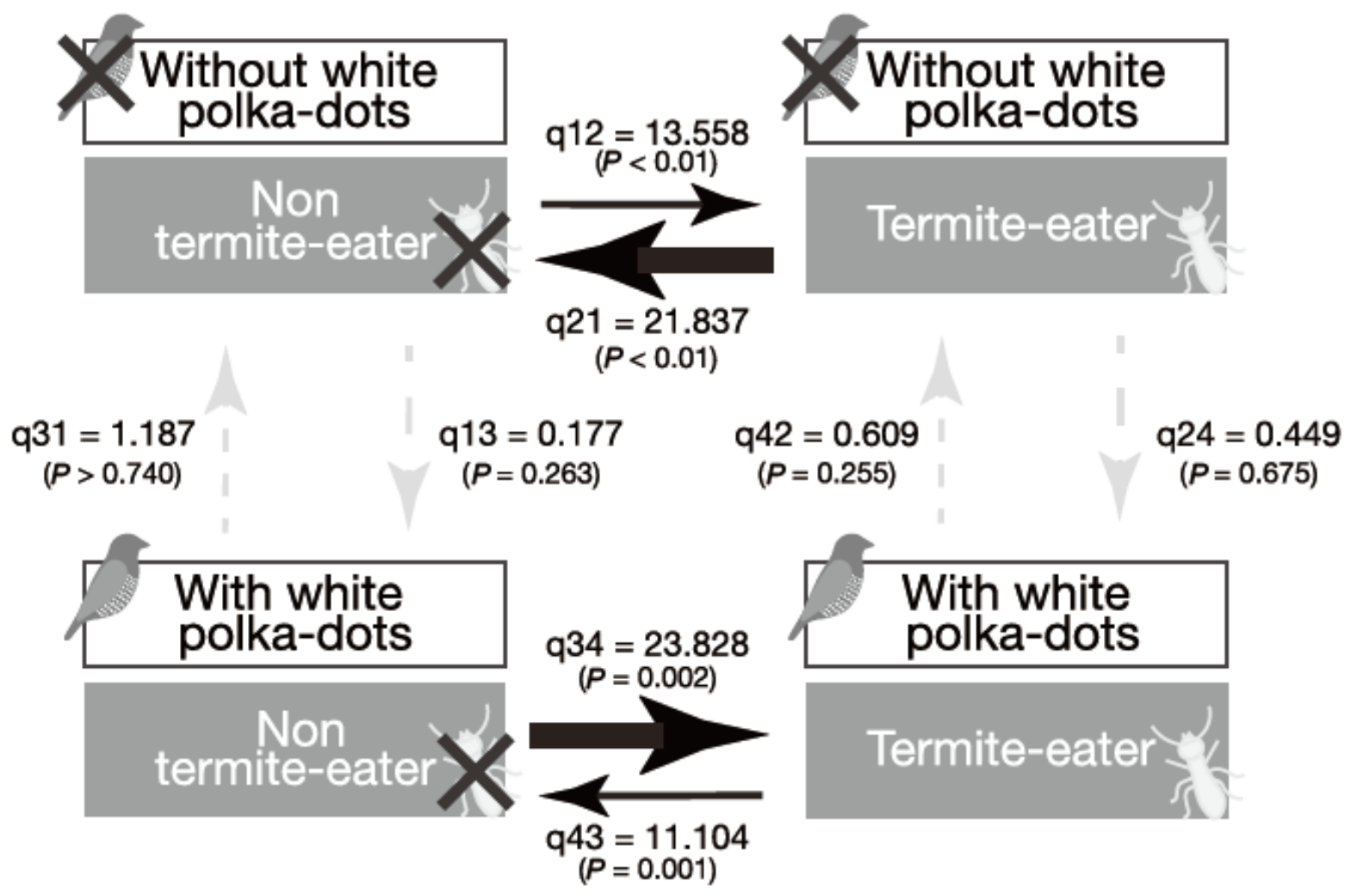

Fig. 3. Evolutionary transitions for the presence/absence of white polka-dots in termite-eaters and non-termite eaters. There are four possible trait states with eight potential transitions among them (gains and losses for each): black filled arrows illustrate the significant evolutionary transitions of these traits, while grey dashed arrows show non-significant evolutionary transitions. 
Table 1.

The effect of diet (either termite or invertebrate eating) on the presence of polka-dots in males (a) and females (b) estimated using phylogenetic logistic regression analysis.

\begin{tabular}{llrrr}
\hline Response variable & \multicolumn{1}{c}{ Explanatory variable } & Coefficient & SE & 95\%CI \\
\hline (a) Male polka-dots & Intercept (Termite-eater) & -1.043 & 0.727 & $(-2.497,0.411)$ \\
& Termite-eater & 0.296 & 0.305 & $(-0.314,0.906)$ \\
& Intercept (Invertebrate-eater) & -1.035 & 0.775 & $(-2.586,0.516)$ \\
& Invertebrate-eater & 0.011 & 0.245 & $(-0.578,0.500)$ \\
& & & & \\
(b) Female polka-dots & Intercept (Termite-eater) & -0.865 & 0.673 & $(-2.210,0.481)$ \\
& Termite-eater & 0.167 & 0.258 & $(-0.348,0.683)$ \\
& Intercept (Invertebrate-eater) & -1.036 & 0.695 & $(-2.426,0.354)$ \\
& Invertebrate-eater & 0.017 & 0.247 & $(-0.478,0.511)$ \\
\hline
\end{tabular}

Table 2.

The effects of the white polka-dot size (either males or females) on termite-eating (a) and invertebrateeating (b) estimated using phylogenetic generalized least-square models. Significant effects of white polka-dot size on (a) termite-eating, not (b) invertebrate-eating. Bold typeface is used when 95\% confidence interval (CI) does not contain zero; therefore, it can be shown as a significant effect.

\begin{tabular}{llccl}
\hline Response variable & \multicolumn{1}{c}{ Explanatory variable } & Coefficient & SE & \multicolumn{1}{c}{ 95\%CI } \\
\hline (a) Termite eating & Intercept (Male dot size) & 0.424 & 0.102 & $(0.625,0.223)$ \\
& Male white polka-dot size (cm) & $\mathbf{2 . 1 9 7}$ & $\mathbf{0 . 9 0 1}$ & $(\mathbf{0 . 4 3 0 , 3 . 9 6 3 )}$ \\
& Intercept (Female dot size) & 0.421 & 0.101 & $(0.223,0.619)$ \\
& Female white polka-dot size (cm) & $\mathbf{2 . 4 5 6}$ & $\mathbf{0 . 8 3 5}$ & $(\mathbf{0 . 8 2 0 , 4 . 0 9 2 )}$ \\
& & & & \\
(b) Invertebrate & Intercept (Male dot size) & 0.803 & 0.092 & $(0.984,0.622)$ \\
eating & Male white polka-dot size $(\mathrm{cm})$ & 0.936 & 0.767 & $(-0.567,2.439)$ \\
& Intercept (Female dot size) & 0.095 & 0.610 & $(0.610,0.984)$ \\
& Female white polka-dot size $(\mathrm{cm})$ & 1.034 & 0.727 & $(-0.391,2.459)$ \\
\hline
\end{tabular}

